\title{
Editorial Editorial
}

\section{Hacia la constitución de un campo sobre las espacialidades de la intervención social}

\author{
Towards the constitution of a field about the spatialities of social \\ intervention
}

\section{Rumo à constituição de um campo sobre as espacialidades da intervenção social}

\section{Felipe Saravia Cortés}

Trabajador Social, Magíster en desarrollo local y regional, Doctor en ciencias sociales en estudios territoriales

Editor general Revista Transformación Socio-Espacial

Académico del Departamento de Ciencias Sociales, Universidad del Bio Bio

Email: fsaravia@ubiobio.cl

En un contexto de una amplia proliferación de revistas académicas que abordan estudios geográficos, territoriales, urbanos, rurales, entre otros, cabe cuestionarse si tiene sentido el esfuerzo asociado a la creación de una más. ¿Con qué fin específico podría justificarse la creación de la revista Transformación SocioEspacial (TSE)?

La respuesta se sustenta en el supuesto de que, si bien el amplio espectro de estudios espaciales cuenta con diversas revistas académicas que constituyen sus vías de comunicación, de producción científica e intelectual, ello no es así en el caso del entrecruzamiento de los estudios que desde las ciencias sociales abordan lo espacial y los procesos de transformación asociados a intervenciones sociales. Es probable que ello sea así debido a que dicho entrecruzamiento no tenga en la actualidad la suficiente solidez como para ser considerado un campo o subcampo científico, o quizá también, en el sentido inverso -aunque no de forma contrapuesta-, puede ser que dicho campo no haya logrado consolidarse precisamente porque no cuenta con espacios de debate y comunicación que permitan la legitimación de su existencia.

La cuestión de si lo espacial de los procesos de intervención y transformación social en general, constituye efectivamente un campo, es un asunto que pretendemos abordar desde la práctica. Es decir, abrimos este espacio como una forma de propiciar el entrecruzamiento de campos mencionado, buscando intersecciones no solo entre el estudio de lo espacial y el de la intervención social, sino la intersección entre disciplinas diversas implicadas en este cruce -asumiendo en ello una clara postura a favor de la transdisciplinariedad en el abordaje de la realidad-. En esta apuesta subyace una lectura Lefebvriana del espacio que requiere de perspectivas unitarias que traspasan las disciplinas: 
"El habitar y la vivienda -el «hábitat», como se dice- conciernen a la arquitectura. La ciudad y el espacio urbano son propios de un dominio especializado: el urbanismo. En cuanto al espacio más amplio, el territorio (regional, nacional, continental o mundial) es competencia de los planificadores y los economistas. Algunas veces esas «especialidades» se insertan bajo el auspicio de un actor privilegiado, el político. Otras veces, sus respectivos dominios se sitúan al margen los unos de los otros, abandonando todo proyecto común y cualquier hermandad teórica. Una teoría unitaria debería poner fin a esta situación" (Lefebvre 2013:72).

Nos proponemos avanzar también hacia un relacionamiento estrecho con los actores de los procesos de transformación socioespacial, a diferencia de lo que creemos generalmente ocurre en las revistas académicas. Por ello, pensamos TSE como una plataforma no solo escrita, sino transmedia -lo que incluye programa radial y videos-, que facilite la divulgación amplia del conocimiento de los procesos y experiencias a los que hacen referencia los artículos publicados, y que facilite también la divulgación de informaciones producidas desde movimientos y organizaciones sociales. Estamos, entonces, frente a un desafío importante: cuestionar de forma sostenida y seria la forma en que hacemos ciencia, la forma en que la comunicamos, e incluso para qué la hacemos. El horizonte en la búsqueda de respuestas a este cuestionamiento no es otro que las luchas diversas por sociedades más justas. Para ello buscaremos publicar artículos de investigación empírica y teórica que idealmente sean fruto de procesos de construcción colectiva de conocimientos, que se vinculen de forma estrecha con procesos de transformación socioespacial, y que tengan una clara mirada transdisciplinaria.

En este primer número, este desafío es enfrentado en primer lugar por Rogério Haesbaert, profesor de Geografía de la Universidad Federal Fluminense (Río de Janeiro, Brasil), que en su artículo "Retomando un debate: límites en el espacio-tiempo", desarrolla una concepción teórica crítica sobre los conceptos de límite y frontera, con amplias implicancias para los procesos de transformación socioespacial. Su trabajo constituye un referente importante para entender estos elementos constituyentes del espacio.

En segundo lugar Barreto, Carvalho y Mayorga, en su artículo "Narrativas em disputa: o desastrecrime da Samarco/Vale/BHP na Bacia do Rio Doce (MG, Brasil)", realizan un meta-análisis de la producción narrativa en torno a lo que denominan como el desastre y crimen producido, a raíz de la interrupción de la presa de relaves de Fundão en 2015, dejando en evidencia cómo la producción científica puede favorecer la legitimación de posturas, ya sea a favor de las poblaciones afectadas por el desastre, o de los actores empresariales con responsabilidad en la ocurrencia de este. En dicho contexto, las autoras abogan por una ciencia al servicio de la población subalterna y dominada, afectada por desastres como el que es descrito en el artículo, y que resulta reflejar situaciones en todo el territorio latinoamericano, en las que el extractivismo sigue generando problemas socio-ambientales de gran espectro.

En tercer lugar, Tapia y Hierro realizan un trabajo relativamente similar, en el que analizan el concepto espacio público como herramienta ideológica en el caso de Ciudad de México, a partir de la revisión de un conjunto de documentos oficiales asociados a procesos de intervención urbanística. Llegando a conslusiones semejantes a las del artículo anterior, los autores postulan que los conceptos pueden ser usados para favorecer procesos colectivos en favor de mayor justicia social y autonomía, o como forma de legitimar perspectivas hegemónicas de dominación.

El cuarto artículo, de las autoras Cejas, Mandrini y Laria, titulado "Hábitat campesino desde un enfoque integral: análisis de una experiencia de diseño colectivo", sistematiza una experiencia concreta de diseño en conjunto con habitantes de una zona rural en Argentina. Se enfatiza en una perspectiva decolonial del trabajo realizado, dando cuenta de la puesta en práctica de procesos de diálogo de saberes, en la lógica propuesta por Boaventura de Sousa Santos. 
Por último, el artículo de Carrera, Baeza y Villalobos, titulado "Apropiaciones territoriales y transformaciones socio-espaciales del maritorio de Chiloé", da cuenta de las transformaciones en las apropiaciones discursivas de un territoriomaritorio específico: el caso de Chiloé, en el sur de Chile. En dicho material, se muestra cómo se ha impuesto en la actualidad una racionalidad económica hegemónica como motor de transformación social y se plantea la urgencia de la búsqueda de alternativas a esta, ya que invisibiliza y niega otras formas de apropiación del territorio, propias del pueblo subalternizado.

En suma, comenzamos este primer número de nuestra revista TSE, con una marcada perspectiva crítica respecto de los asuntos espaciales, acogiendo artículos que hacen hincapié en la relevancia de los procesos de generacion de conceptualizaciones sobre el territorio, y en los procesos de dominación y legitimación subyacentes a los mismos. En la generación de esta plataforma para el abordaje de los estudios territoriales y las transformaciones socioespaciales, es que podemos encontrar muchas respuestas a la pregunta con la que abre esta editorial. Este es un espacio de comunicación científica, que se justifica precisamente ante la urgencia de legitimar la producción científicacrítica, que no solo devela la función ideológica de aquella ciencia pretendidamente neutra frente la realidad en sus dimensiones social y espacial, sino que abiertamente se pone al servicio de los grupos subalternizados y dominados.

Para concluir, destacamos el hecho de haber recibido una cantidad importante de trabajos (no todos fueron publicados en este número de lanzamiento), procedentes de diversos rincones de la América Latina. Ello nos permite comenzar a sentir, pensar y proyectar fuertemente la impronta latinoamericana que debe poseer la comunicación científica en este sur, y en particular en nuestra publicación, dando cuenta de las necesidades e intereses específicos de nuestros territorios. Dicha impronta se irá ampliando y densificando a lo largo de nuestros próximos números. 